\title{
UJI PERFORMANSI KONTROL SUHU DAN KELEMBABAN MENGGUNAKAN VARIASI KONTROL DIGITAL DAN KONTROL SCHEDULING UNTUK PENGAWETAN BUAH DAN SAYURAN
}

\author{
Rofan Aziz, Karsid \\ Jurusan Teknik Pendingin dan Tata Udara, Politeknik Negeri Indramayu \\ e-mail: rofan.aziz@yahoo.com
}

\begin{abstract}
Abstrak-Saat ini proses pengawetan buah dan sayuran di Indonesia masih dilakukan dengan cara tradisional. Banyak buah dan sayuran pasca panen langsung dijual ke pasar. Sehingga pada saat panen, kuantitas komoditi tersebut melimpah dan disaat waktu panen selesai komoditi tersebut habis dan langka. Pada pengawetan buah dan sayuran, suhu dan kelembaban relatif merupakan dua variabel kontrol yang saling mempengaruhi. Dimana kenaikan dan penurunan suhu akan berakibat pada perubahan kelembaban relatif. Pada penelitian kali ini dilakukan dua variasi kontrol yaitu kontrol digital dan kontrol scheduling untuk mengetahui karakteristik hubungan suhu dan kelembaban relatif. Hasil dari uji kedua variasi kontrol tersebut didapatkan bahwa kontrol digital memiliki waktu puncak yang cepat baik untuk mencapai set point suhu dan kelembaban. Sedangkan kontrol scheduling kenaikan kelembaban mengikuti kenaikan suhu.
\end{abstract}

\section{Kata Kunci : Suhu, Kelembaban Relatif, Buah, Sayuran, Pengawetan}

\begin{abstract}
Currently the preservation of fruit and vegetables in Indonesia is still done with traditional. Most post-harvest handling of fruits and vegetables in Indonesia directly sold into the market. So at harvest, the quantity of the commodity is abundant and when the time of harvest finished exhausted and rare commodity. In the fruit and vegetable preservation, temperature and relative humidity are two control variables that influence each other. Where the increase and decrease in temperature will result in changes in relative humidity. In this research carried out two variations control the digital control and control scheduling to determine the characteristics of the relationship of temperature and relative humidity . Results from both trials showed that the variation of the control of digital control has a good quick peak time to reach the set point temperature and humidity. While scheduling control humidity rise with the increase in temperature.
\end{abstract}

Keywords : Temperature, Relative Humidity, Fruits, Vegetables, preservation.

\section{PENDAHULUAN}

Saat ini sayur dan buah-buahan pasca panen masih dikelola secara tradisional. Hasil sayur dan buah pasca panen langsung dikemas dan dijual kepasar. Sehingga pada saat panen buah dan sayuran akan melimpah. Padahal produk sayuran dan buah harus dijaga kuantitasnya untuk menjaga stabilitas harga komoditi tersebut.

ntuk menjaga kualitas buah dan sayuran dilakukan proses pendinginan awal (precooling). Proses pendinginan awal untuk penghilangan panas radiasai dari lingkungan yang diserap oleh produk langsung setelah panen, dan sebelum dimasukan ke mesin pengawetan buah dan sayuran (cool storage)[1]. Proses pendinginan tersebut jika tidak dilakukan akan merusak mutu dan memperpendek umur buah dan sayuran[1].
Kontrol suhu dan kelembaban pada penyimpanan buah dan sayuran akan menghambat laju respirasi. Dengan pengurangan laju respirasi kesegaran buah dan sayuran akan tetap terjaga[1].

Suhu dan kelembaban merupakan dua besaran kontrol yang saling mempengaruhi. Dimana ketika suhu berubah, kelembaban udara akan ikut berubah[2].

Untuk memudahkan pengambilan data suhu dan kelembaban diperlukannya suatu alat yang dapat menginformasikan keadaan tersebut secara terus menerus yaitu dengan data akuisisi menggunakan komputer.

Berdasarkan permasalahan di atas, maka dilakukan penelitian pengkondisian suhu dan kelembaban dengan menggunakan dua metode yaitu kontrol on-off terhadap suhu dan kelembaban dan kontrol schedulling pompa air. Dengan ini akan dibandingkan efisiensi kontrol 
suhu dan kelembaban menggunakan kedua metode kontrol tersebut. Sehingga didapatkan metode paling efisien dan tercepat untuk mengkondisikan suhu dan kelembaban pada mesin pengawet buah dan sayuran (cool storage) tersebut.

Agar dapat dipantau secara terus-menerus maka ditanam sistem akuisisi data dengan menggunakan komputer. Sistem akuisisi data ini dirancang agar dapat merekam data suhu dan kelembaban selama batas waktu yang diinginkan.

\section{METODOLOGI PENELITIAN}

\subsection{Perancangan Sistem}

Secara garis besar dari keseluruhan sistem pada alat ini sesuai dengan blok diagram pada Gambar 1.

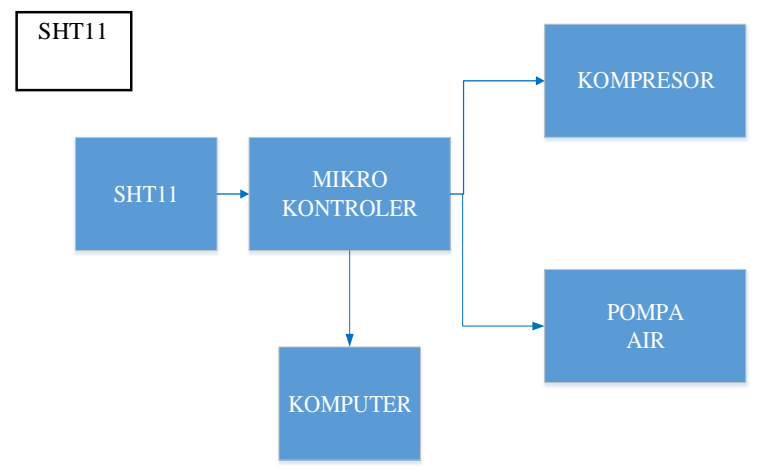

Gambar 1. Blok diagram sistem pengawet buah dan sayuran.

Proses yang dilakukan pertama kali adalah sensing suhu dan kelembaban oleh sensor SHT11, data diteruskan ke mikro kontroler untuk dilakukan proses eksekusi program dan meng aktifkan aktuator berupa kompresor dan pompa air.

Data dari mikrokontroler alan diteruskan ke komputer sebagai sistem data akuisisi agar dapat tersimpan dan terpantau secara terus-menerus (real time).

\subsection{Perancangan Perangkat Keras}

\subsubsection{Arduino UNO}

Pada penelitian ini, digunakan sistem mikro kontroler Arduino tipe UNO. Arduino merupakan sebuah platform komputasi fisik yang bersifat open source dengan board input dan output yang sederhana[3]. Arduino berfungsi sebagai sistem pengendali, pemroses data serta mengirimkan data ke komputer untuk disimpan dan ditampilkan secara terus-menerus (real time).

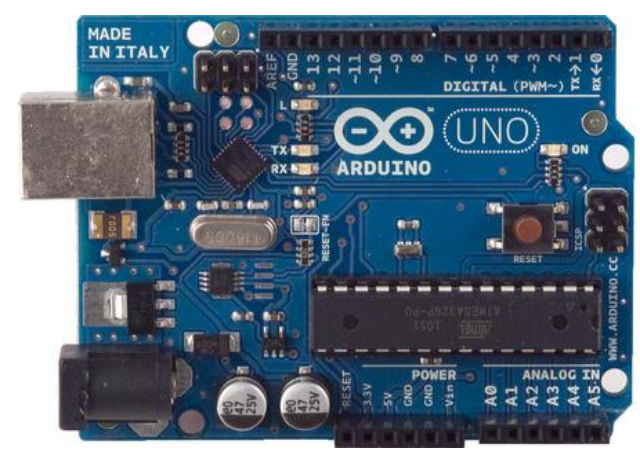

Gambar 2. Mikrokontroler Arduino Uno (Sumber : www.arduino.cc)

\subsubsection{SHT 11}

SHT1x (termasuk SHT10, SHT11 dan SHT15) adalah termasuk keluarga sensor dari Sensirion untuk mengukur kelembaban relatif dan suhu permukaan. Sensor ini mengintegrasikan elemen sensing ditambah pemrosesan sinyal sehingga memberikan output digital sepenuhnya yang telah dikalibrasi[4].

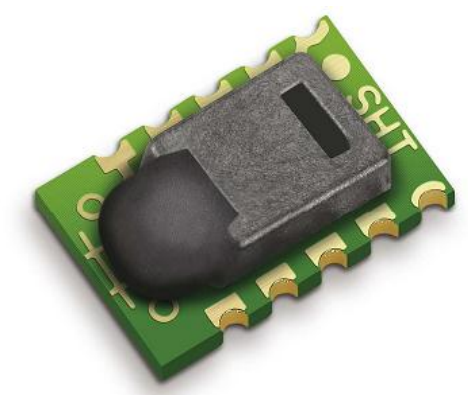

Gambar 3. Sensor SHT11 [4]

\subsubsection{Relay}

Relay adalah sebuah saklar yang dioperasikan secara elektrik. Kebanyakan prinsip kerja relay menggunakan prinsip elektromagnet untuk menggerakkan dan mengoperasikan switch. Penggunaan relay digunakan untuk mengendalikan rangkaian dengan sinyal dengan daya rendah (dengan isolasi listrik lengkap antara kontrol dan sirkuit yang akan dikontrol), atau di mana beberapa sirkuit harus dikontrol oleh satu sinyal[5]. 


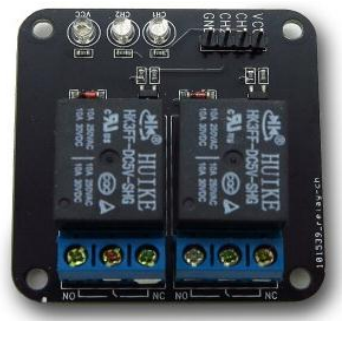

Gambar 4. Dua Channel Relay Module

(Sumber : iteadstudio.com)

\subsubsection{Mesin Pengkondisi Suhu dan} Kelembaban.

Pada penelitian ini dirancang mesin pengkondisi suhu dan kelembaban dengan menggunakan mesin pendingin dan pompa air yang dialirkan pada kain kasa untuk menjaga kelembaban didalam kabin.

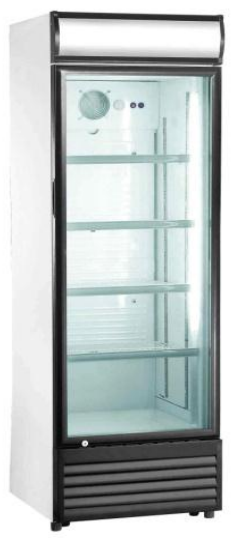

Gambar 5. Mesin Pengkondisi Udara

(Sumber : www.ecvv.com)

\subsection{Perancangan Perangkat Lunak}

\subsubsection{Kontrol Digital}

Kontrol digital pada penelitian ini diambil dari kondisi kompresor dan pompa air yang hanya diberikan perintah On dan Off ketika berada pada kondisi terkontrol.

Pada penelitian ini dilakukan pengaturan set point suhu pada $2,5^{\circ} \mathrm{C}$, ketika kurang dari set point kompresor akan Off dan akan On kembali ketika suhu dalam kabin mencapai $5,5^{\circ} \mathrm{C}$.

Relativ Humidity (RH) atau kelembaban relatif merupakan variabel kontrol ke dua dalam penelitian ini. Ketika RH kurang dari 70\%, maka pompa air akan menyala sampai RH tercapai. Ketika RH lebih dari 70\%, Pompa air akan Off dan pompa akan kembali On ketika RH kurang dari $65 \%$.

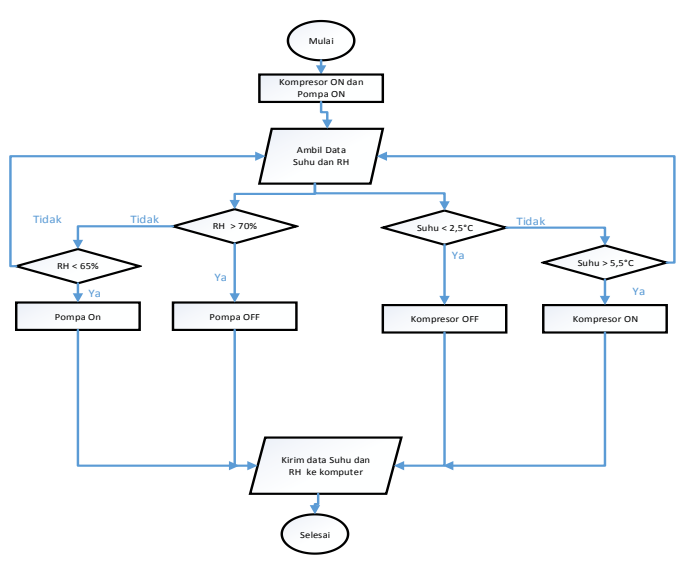

Gambar 6. Flowchart Kontrol Digital

\subsubsection{Kontrol Schedulling.}

Pada Variasi kontrol ke 2 dilakukan pewaktuan penggunaan pompa air. Dimana pompa hanya akan bekerja selama 1 menit, dan off selama 209 menit, kondisi ini akan terus berulang.

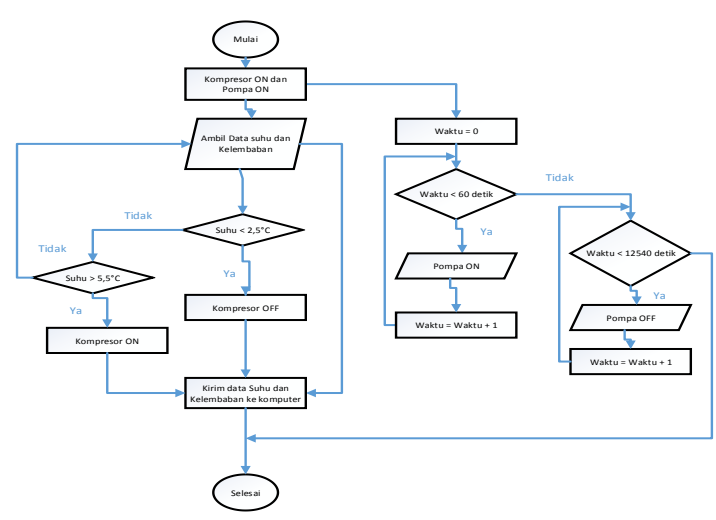

Gambar 7. Flowchart Kontrol Schedulling

\subsection{Sistem kontrol suhu dan kelembaban}

Sistem kontrol menggunakan arduino UNO dengan relay sebagai Saklar pemutus arus dan menggunakan sensor suhu dan kelembaban SHT11.

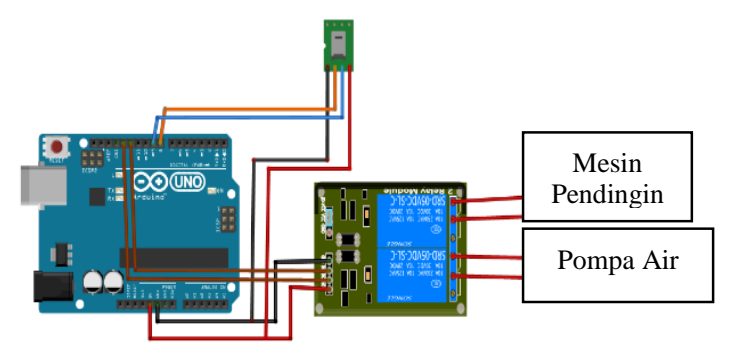

Gambar 8. Sistem Kontrol Suhu dan kelembaban 
Pada saat mesin bekerja Arduino akan membaca suhu dan kelembaban kabin dan akan melakukan kerja sesuai dengan kondisi kontrol yang diinginkan.

Hasil suhu dan kelembaban tersebut akan di kirim ke komputer sebagai pengumpul data suhu dan kelembaban secara terus menerus.

\section{HASIL DAN PEMBAHASAN}

\subsection{Data Hasil Kontrol Digital}

Hasil pengukuran menggunakan skema kontrol digital didapatkan waktu puncak (rise time) suhu set point tercapai selama 1 jam 5 menit. Untuk kontrol digital kenaikan kelembaban berlangsung cepat hanya 6 menit setelah mesin bekerja.

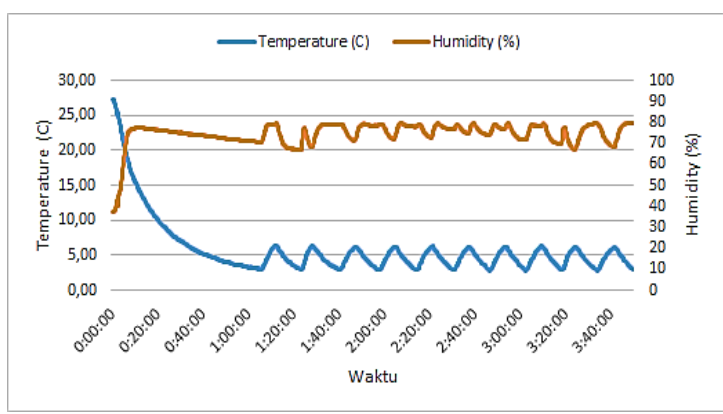

Gambar 9. Grafik Performansi Kontrol Digital

\subsection{Data Hasil Kontrol Scheduling}

Unjuk kerja waktu puncak (rise time) kontrol Scheduling tercapai selama 2 jam mesin bekerja. Kenaikan kelembaban berlangsung lambat sampai suhu kondisi kelembaban baru sampai pada set point yang di inginkan.

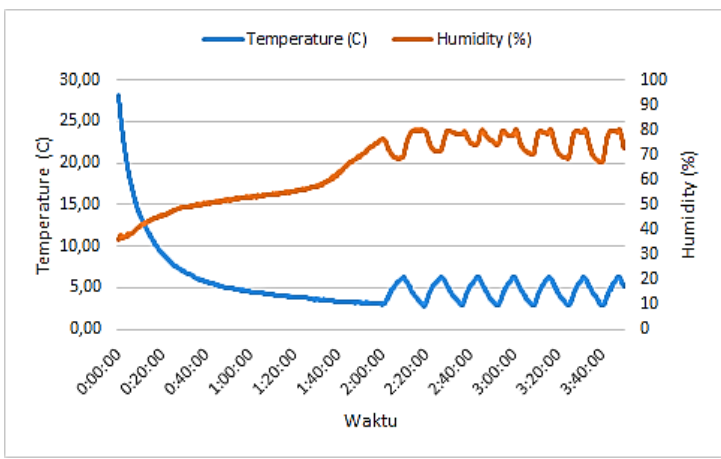

Gambar 10. Grafik Performansi Kontrol Scheduling

\subsection{Perbandingan Performansi Suhu}

Dari perbandingan performansi suhu kedua variasi kontrol, dapat dilihat bahwa kontrol digital lebih cepat mencapai suhu set point daripada kontrol Schedulilng. Setelah masingmasing mencapai set point kerja kontrol identik sama.

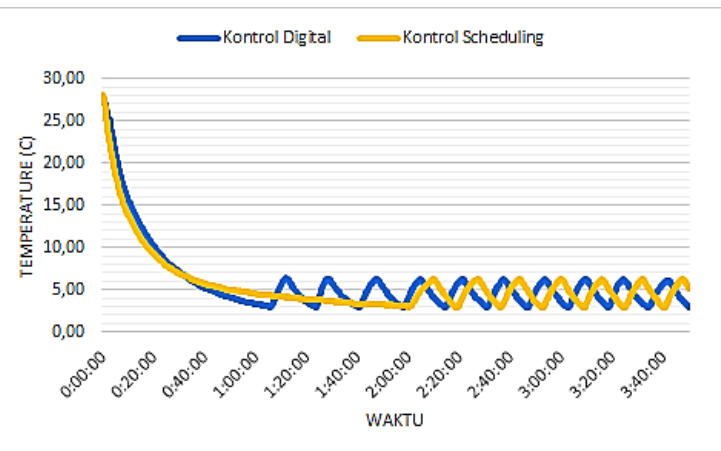

Gambar 11. Grafik Perbandingan Performansi Suhu

\subsection{Perbandingan Performansi Kelembaban}

Uji performansi kedua variasi kontrol terhadap kelembaban relatif dalam kabin didapatkan bahwa kontrol digital lebih cepat mencapai setpoint kelembaban dibandingkan dengan kontrol schedulilng. Akan tetapi kenaikan kelembaban untuk kontrol scheduling lebih perlahan sehingga bisa mengikuti kenaikan suhunya.

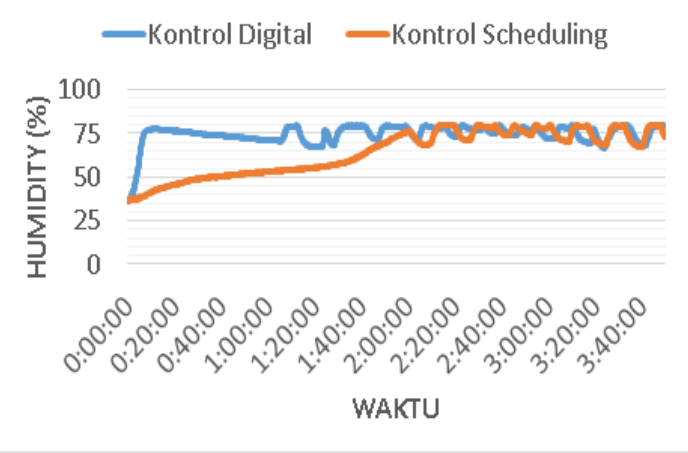

Gambar 12. Grafik Perbandingan Performansi kelembaban

\section{KESIMPULAN}

Penggunaan kontrol digital pada mesin pengawetan buah dan sayuran memiliki performansi yang baik dan cepat mencapai 
setpoint yang diinginkan. Sedangkan performansi sistem kontrol scheduling walaupun lambat mencapai setpoint yang di inginkan, tetapi kenaikan kelembaban relatifnya mengikuti penurunan suhu.

\section{DAFTAR PUSTAKA}

[1] L. Kitinoja, A. A. Kader, "Small Sacale Postharvest Handling Practices: A manual for Horticultural Crops", University of California, Davis Postharvest Technology Research and Information Center, 2002.

[2] T. Bartelt, "Industrial Control Electronics”, Cengage Learning, 2005.

[3] D. Artanto., "Interaksi Arduino dan Labview”, Elek Media Komputindo, 2012.

[4] Sensirion, "Datasheet SHT1x (SHT10, SHT11, SHT15) Humidity and Temperature Sensor IC", SENSIRION, Switzerland, 2011.

[5] I.R. Sinclair, "Sensors and Transducers (3rd ed.)", Elsevier, 2001.

[6] I.M.S. Utama, N.S., "Antara, Pasca Panen Tanaman Tropika: Buah Dan Sayur", Tropical Plant Curriculum Project, Udayana University. 2013.

\section{Biodata Penulis}

Rofan Aziz, Dosen Teknik Pendingin dan Tata Udara Politeknik Negeri Indramayu bidang Keahlian Instrumentasi dan Kontrol.

Karsid, Dosen Teknik Pendingin dan Tata Udara Politeknik Negeri Indramayu bidang Keahlian Instrumentasi dan Kontrol. 